\title{
Adrenal medulla of AS/AGU rats: a histological and immunohistochemical study
}

\author{
M.A. Al-Fayez ${ }^{1}$, M. Atteya ${ }^{1,2}$, R.A. Mohamed ${ }^{1,2}$, A.M. Ahmed ${ }^{1}$, A.H. Alroalle1, \\ M. Salah Khalili3, ${ }^{4}$, M. Al-Ahmed ${ }^{5}$, A. Payne ${ }^{6}$ \\ ${ }^{1}$ Department of Anatomy, College of Medicine, King Saud University, Riyadh, Saudi Arabia \\ 2Department of Histology, Faculty of Medicine, Cairo University, Cairo, Egypt \\ ${ }^{3}$ Histology Department, Faculty of Medicine, Suez Canal University, Ismailia, Egypt \\ ${ }^{4}$ College of Medicine, King Saud University, Riyadh, Saudi Arabia \\ ${ }^{5}$ Department of Quantitative Analysis, College of Business Administration, King Saud University, Riyadh, Saudi Arabia \\ 6Institute of Biomedical and Life Science, Glasgow University, Glasgow, United Kingdom
}

[Received: 14 March 2016; Accepted: 19 May 2016]

Background: The outcome of the autograft therapy for Parkinson's disease including autologous cells from adrenal medulla was disappointing. This could be attributed to the pathological process in Parkinson's disease affecting cells of the adrenal medulla. This study was performed to investigate the histopathological changes in the adrenal medulla of AS/AGU rat, a model of Parkinson's disease, in comparison with Albino Swiss (AS) rats.

Materials and methods: A total of 24 male AS rats were divided into four groups, each of 6 animals: AS W1 - AS rats aged 1 week; AS adult - AS adult rats; AS/ IAGUW1 - AS/AGU rats aged 1 week; and AS/AGU adult - AS/AGU adult rats. The rats were sacrificed and the adrenal glands were dissected and processed for histological staining with haematoxylin and eosin and periodic acid Schiff and for immunohistochemical staining for $\$ 100$ protein, ubiquitin and tyrosine hydroxylase.

Results: The histological investigation of the adrenal medulla of AS/AGU rats showed vascular congestion, inflammatory cellular infiltration, pyknotic nuclei, necrotic chromaffin cells and medullary inclusion bodies. The immunohistochemical investigation of AS/AGU rats showed a statistically significant decrease in the expression of 100 protein, ubiquitin and tyrosine hydroxylase compared to AS rats. Conclusions: The histological and immunohistological changes in the adrenal medulla could explain the failure of outcome of adrenal autograft therapy in Parkinson's disease. (Folia Morphol 2017; 76, 1: 28-37)

Key words: AS rats, AS/AGU rats, Parkinson's disease, adrenal medulla, histology, immunohistochemistry, S100, ubiquitin, tyrosin hydroxylase

\section{INTRODUCTION}

Parkinson's disease (PD) is a chronic, progressive neurodegenerative disorder of unknown aetiology that affects $1 \%$ of the population over 55 years of age. PD is characterised by impairment of movement including resting tremors, bradykinesia (slowing of voluntary movements), altered gait, muscular rigidity, postural instability, and flat (unemotional, fixed)

Address for correspondence: Dr. M.A. Al-Fayez, Department of Anatomy, College of Medicine, King Saud University, PO Box 2925 (28), Riyadh 11461, Saudi Arabia, tel: +966(11)4670809, fax: +966(11)4671300, e-mail: alfayez@ksu.edu.sa 
facial expression. It results from loss of dopamineproducing neurons in the substantia nigra pars compacta and the presence of intracytoplasmic inclusions known as Lewy's bodies that are formed primarily from alpha-synuclein and ubiquitin [2]. These pathological changes occur in the central and peripheral nervous system and adrenal medulla [2].

The AS/AGU rat has a spontaneously recessively point mutated (agu) gene coding for the gamma isoform of protein kinase C (PKC- $\gamma$ ) resulting in a failure to release dopamine in the striatum of Albino Swiss (AS) rat $[12,16]$. The AS/AGU rat is characterised by serious movement impairments such as rigidity, staggering gait, tendency for the hind quarters to slip over every few steps, slight whole body tremor, and difficulty in initiating movement $[9,12,36]$. The movement impairment is resulting from reduced tyrosine hydroxylase levels, which reflects the degeneration of dopaminergic cells, in substantia nigra pars compacta, subthalamic nucleus, and ventrolateral thalamus [37]. These manifestations make the AS/ /AGU rat a unique model for investigations of the integrity of dopaminergic systems in PD [37].

Oral administration of dopamine or its agonists is the main treatment of patients complaining of PD symptoms. Continuous administration of dopamine results in several undesirable side effects including drug-induced dyskinesias and unresponsiveness of patients to therapy [34]. Side effects of dopamine therapy and the limited brain capacity for self-repair encouraged scientists to perform trials on cell-based therapy including adrenal medullary autograft [26].

Using autografts, as autologous cellular sources of dopamine, has been chosen for the treatment of PD because of the ease of tissue collection without the ethical and immunological problems inherent in allogeneic and xenogeneic tissue. The autografts therapy for PD included autologous cells from sympathetic ganglion neurons, carotid body, and adrenal medulla, although overall results to date have been disappointing [45].

The first clinical trial of using adrenal medullary autograft to caudate nucleus showed a dramatic response of PD symptoms in 2 patients [30] then the results showed less favourable outcomes in terms of decreased positive effects of pharmacological treatment [19].

Adrenal medulla consists of chromaffin cells, the majority of cells, which convert the amino acid tyros- ine into adrenaline, noradrenaline, and dopamine; sustentacular cells, which are spindle or branched cells at the periphery of nests of chromaffin cells and are homologous in nature with Schwann cells; and ganglion cells [39].

S100 proteins are normally present in cells derived from the neural crest (Schwann cells and melanocytes), chondrocytes, adipocytes, myoepithelial cells, macrophages, Langerhans cells $[14,46]$, and dendritic cells [41]. It was found that $\mathrm{S} 100$ protein is detected in the normal adrenal medullary tissue. S100 expression is increased in the cytoplasm of degenerative adrenal chromaffin cells as a result of their penetration by the cytoplasmic processes of sustentacular cells [10].

It was noticed that inhibition of ubiquitin-proteasome degradation system (UPS) and tyrosine hydroxylase $(\mathrm{TH})$ play the principal role in the pathogenesis of PD. The UPS is responsible for degradation of many cellular proteins [15].

Tyrosine hydroxylase is present in all dopaminergic cells and catalyses the formation of L-DOPA resulting in dopamine synthesis [1]. TH is found in diverse tissues comprising the central and sympathetic nervous system and adrenal medulla [20]. The activity of TH is often as low as $25 \%$ of healthy age-matched controls. However, in Parkinsonism, this activity could fall to $10 \%[20]$.

Post-mortem studies showed poor survival of grafted tissue $[25,28]$ after an autologous adrenal medullary transplantation, with few surviving chromaffin positive cells and complete absence of cells stained with TH at the graft site [27]. These data give the possibility of pathological changes affecting the dopamine secreting cells of the central nervous system, as well as those of the peripheral nervous system and the adrenal medulla.

This study aimed to investigate the histological and immunohistochemical changes in the adrenal medulla of AS and AS/AGU rats in a trial to explain the non-effectiveness of adrenal medullary autografts as an option for the treatment of PD.

\section{MATERIALS AND METHODS}

\section{Animals}

A total of 12 male Albino Swiss (AS) rats and 12 male AS/AGU rats were divided into four groups, each of 6 animals: AS W1 - AS rats aged 1 week; AS adult - AS adult rats; AS/AGU W1 - AS/AGU rats aged 1 week; and AS/AGU adult - AS/AGU adult rats. 
The rats were obtained from the Experimental Animal Centre in College of Medicine, King Saud University, Saudi Arabia. The rats were maintained with water and food, ad libitum, at constant humidity and temperature. Under anaesthesia, the rats were euthanised by cardiac perfusion with mammalian Ringer's solution and $4 \%$ paraformaldehyde in 0.1 M phosphate buffer. The animals were dissected and adrenal glands were excised and stored in 4\% paraformaldehyde in phosphate buffer over-night, then embedded in paraffin wax at $57^{\circ} \mathrm{C}$. Serial sections were cut at $4 \mu \mathrm{m}$ and stained for histological and immunohistochemical studies. All the experimental procedures were conducted according to the Guidelines for the Care and Use of Laboratory Animals of the College of Medicine Research Centre (CMRC) at King Saud University and conform to the Guide for the Care and Use of Laboratory Animals published by the National Institutes of Health (NIH).

\section{Histological studies}

Haematoxylin and eosin (H\&E) [17] and periodic acid Schiff (PAS) [13] were used for histological evaluation and detection of adrenomedullary inclusion bodies (Lewy's bodies), respectively.

\section{Immunohistochemistry}

Immunostaining of the paraffin sections of the adrenal glands for detection of S100 protein, ubiquitin and $\mathrm{TH}$ were performed using streptavidin-biotinylated horseradish peroxidase (S-ABC) method (Novalink Max Polymer detection system, Novocastra, product NO. RE7280-K). The procedure involved the following steps: endogenous peroxidase activity was inhibited by $3 \% \mathrm{H}_{2} \mathrm{O}_{2}$ in distilled water for $5 \mathrm{~min}$, and then the sections were washed in Tris buffered saline (TRS) (Sigma, T 5030-100 TAB, pH 7.6) twice; 5 min for each. Non-specific binding to antibodies was blocked by incubation with protein block for 5 min (Novocastra). Sections were incubated with anti-S100 antibody (rabbit polyclonal, dilution 1:500) (Cat\# abcam-ab868), anti-ubiquitin mouse monoclonal (ub-A5: sc166553) at dilution of 1:100, and anti-TH antibody (rabbit polyclonal antibody, dilution 1:1000; GenWay Trust-GWB; 760869). All slides were incubated with the primary antibodies for $1 \mathrm{~h}$ at room temperature. Sections were washed in Tris buffer for 3 times; each for $3 \mathrm{~min}$, and then incubated with biotinylated anti-rabbit IgG (Novocastra) for $30 \mathrm{~min}$. This was followed by washing in Tris buffer for 3 times, each for $3 \mathrm{~min}$, and then incubated with Novolink polymer (Novocastra) for $30 \mathrm{~min}$. Then sections were washed in Tris buffer for 3 times; each for $3 \mathrm{~min}$. Peroxidase was detected with working solution of diaminobenzidine (DAB) substrate (Novocastra) for $10 \mathrm{~min}$. Finally, sections were washed in distilled water for $10 \mathrm{~min}$. The sections were counterstained with Mayer's haematoxylin and then mounted in DPX (Dysterene, Plasticizer, Xylene). For negative control sections, the same procedure was followed but with omission of incubation with the primary antibodies. Positive controls for S-100, ubiquitin, and $\mathrm{TH}$ are astrocytes, $\mathrm{HqC2}$ cells, and brain, respectively.

\section{Image analysis}

High-resolution whole-slide digital scans of S100, $\mathrm{TH}$ - and ubiquitin-immunostained sections were created with a ScanScope scanner (Aperio Technologies, Inc.). The digital slide images were then viewed and analysed using the viewing and image analysis tools of Aperio's ImageScope software (Aperio Technologies, Inc.). Five areas, each with the fixed size of $0.066 \mathrm{~mm}^{2}$, were randomly selected per section. To quantify the immunopositive reaction, the colour deconvolution (colour separation) algorithm (Aperio Technologies, Inc.) was set up (by colour calibration) to detect and quantify only the brown colour of DAB positive staining. The algorithm was then run on the selected area to measure the percentage of immunopositive reaction relative to the total analysis area. Cells positive for Lewy's bodies (as visualised in PASstained sections), in 5 randomly selected high-power fields per section, were counted and their percentage, relative to the total number of cells in the field, was calculated using the Manual Tag feature of Image-Pro Plus, Version 6 (Media Cybernetics, Inc.). All image analysis output results were finally exported to Excel sheets and subjected to statistical analysis.

\section{Statistical analysis}

Data collected were subjected to statistical analysis using IBM SPSS Statistics, Version 22. The normality and homogeneity of variances of the data were first checked by Shapiro-Wilk test and Levene's test, respectively. Analysis of variance (ANOVA) was then used for an overall comparison between the studied groups followed by Scheffe's test for post hoc pairwise comparisons. Differences were considered significant when $\mathrm{p}$ was equal to or less than 0.05 . 

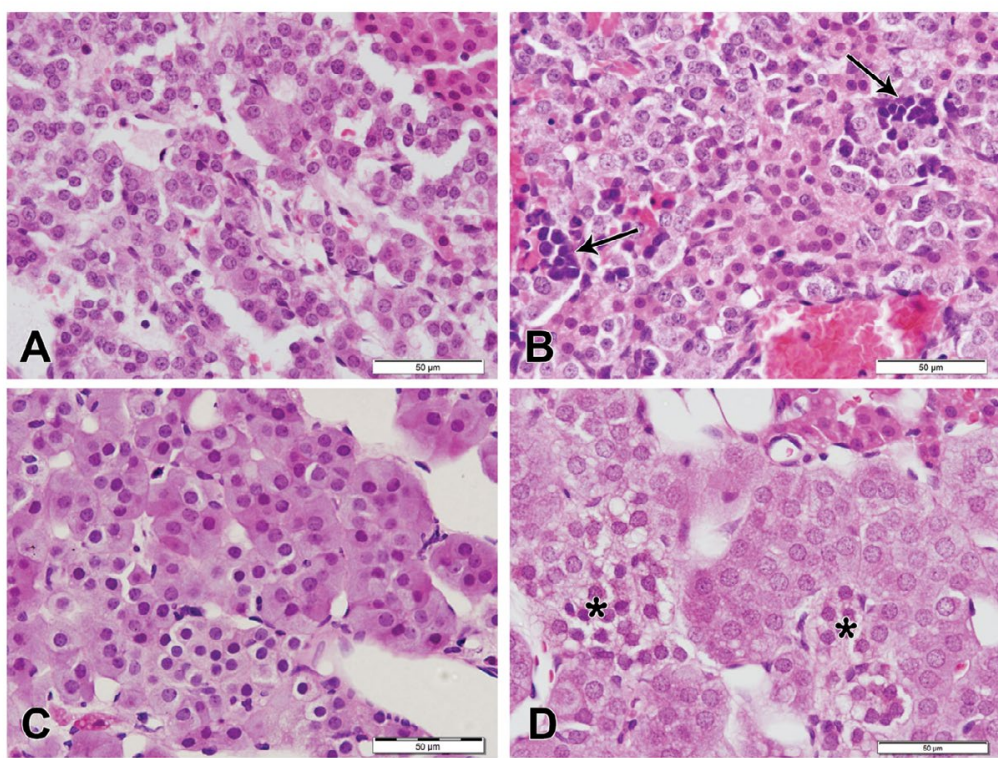

Figure 1. Photomicrographs of haematoxylin and eosin-stained sections of adrenal medulla. Scale bars $=50 \mu \mathrm{m}$. A. One-week-old AS rats showing normal cells; B. One-week-old AS/AGU rats showing multiple foci of inflammatory cellular infiltration (arrows); C. Adult AS rats showing normal cells; D. Adult AS/AGU rats showing large foci of necrotic chromaffin cells (asterisks).

\section{RESULTS}

Haematoxylin and eosin-stained sections of the adrenal medulla from both 1-week-old and adult AS rats showed normal features of chromaffin cells which appeared as polyhedral large cells arranged in cords and clusters. These cords and clusters are separated by blood vessels (Fig. 1A, C). H\&E-stained sections of the adrenal medulla from 1-week-old AS/AGU rats showed vascular congestion and multiple foci of inflammatory cellular infiltration (Fig. 1B). Sections from adult AS/AGU rats showed similar histopathological changes in addition to large foci of necrotic chromaffin cells (Fig. 1D).

Periodic acid Schiff-stained sections of adrenal medulla from both 1-week-old and adult AS rats showed few chromaffin cells with Lewy's bodies, which appeared as PAS-positive spherical inclusion bodies (Fig. 2A, C). However, 1-week-old AS/AGU rats and adult AS/AGU rats showed significantly higher percentages of chromaffin cells with Lewy's bodies compared to 1-week-old AS rats and adult AS rats, respectively (Figs. 2B, D; 6A).

S100-immunostaining of adrenal medulla from AS/AGU rats of both ages showed significantly lower area per cent of immunopositively stained sustentacular cells (Fig. 3B, D) as compared to AS rats of both ages (Figs. 3A, C; 6B). S-100 immunoreaction was detected in both cytoplasm and nucleus of sustentacular cells.

Ubiquitin-immunostaining of adrenal medulla from AS/AGU rats of both ages showed significantly lower area per cent of immunopositively stained chromaffin cells (Fig. 4B, D) compared to AS rats of both ages (Figs. 4A, $C ; 6 C$ ). Ubiquitin immunoreaction was observed in both cytoplasm and nucleus of chromaffin cells. Lewy's bodies were seen as inclusion bodies with immunopositive staining of their periphery. The Lewy's bodies were more numerous in AS/AGU rats of both ages (Fig. 4B, D) compared to AS rats of both ages (Fig. 4A, C).

Tyrosin hydroxylase-immunostaining of the adrenal medulla from AS/AGU rats of both ages showed significantly lower area per cent of immunopositively stained chromaffin cells (Fig. 5B, D) compared to AS rats of both ages (Figs. 5A, C; 6D). TH immunoreaction was demonstrated in the cytoplasm of chromaffin cells. In adults groups, the TH-immunostaining was of mild intensity in AS rats (Fig. 5C) and almost completely negative in AS/AGU rats (Fig. 5D).

\section{DISCUSSION}

The adrenal medulla and the sympathetic nervous system constitute an anatomical and physiological unit [47]. The sympathetic nervous system has already 


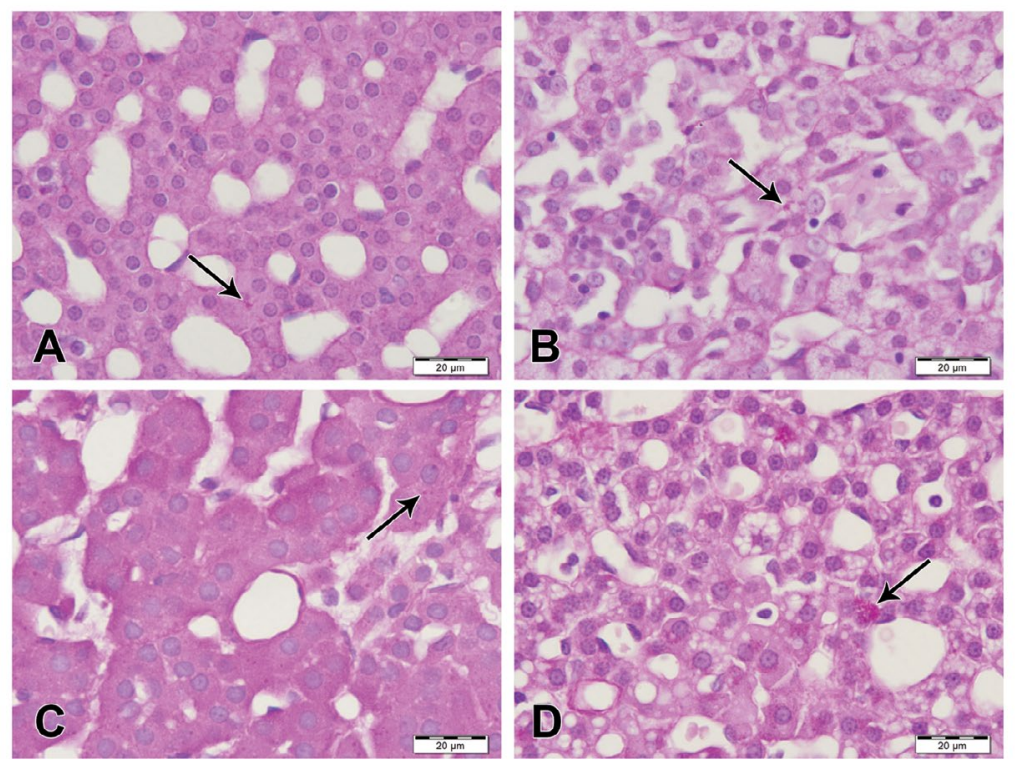

Figure 2. Photomicrographs of periodic acid Schiff (PAS)-stained sections of adrenal medulla. Scale bars $=20 \mu \mathrm{m}$; A. One-week-old AS rats showing few chromaffin cells with PAS-positive medullary bodies (arrow); B. One-week-old AS/AGU rats showing few chromaffin cells with PAS-positive medullary bodies (arrow); C. Adult AS rats showing few chromaffin cells with PAS-positive medullary bodies (arrow); D. Adult AS/AGU rats showing numerous chromaffin cells with PAS-positive medullary bodies (arrow).
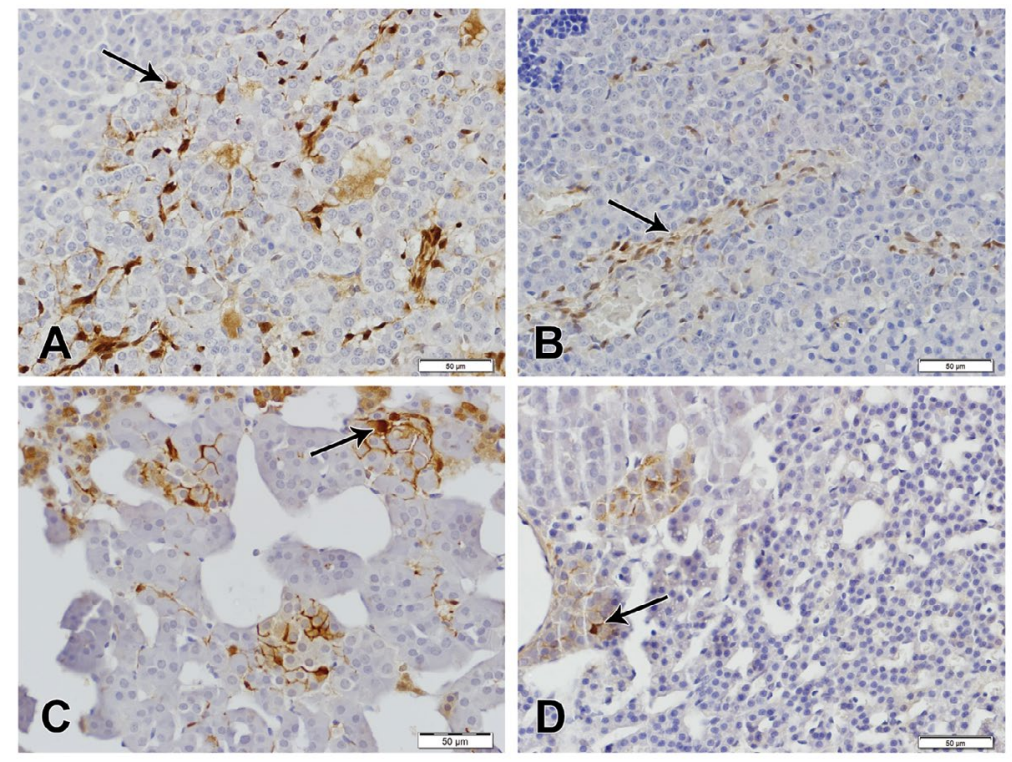

Figure 3. Photomicrographs of S-100 immunostained sections of adrenal medulla. Scale bars $=50 \mu \mathrm{m} ;$ A. One-week-old AS rats showing strong S100 expression in sustentacular cells (arrow); B. One-week-old AS/AGU rats showing weak positively immunostained cells (arrow); C. Adult AS rats showing increase in the number and volume of $S 100$ positively immunostained cells (arrow); D. Adult AS/AGU rats showing marked decrease in number and size of $S 100$ positively immunostained cells (arrow).

been recognised as a pathological site in PD [44]. PD is frequently accompanied by a variety of autonomic symptoms. The adrenal medulla is a major component of the autonomic nervous system, thus the adrenal medulla appears to be a target of the peripheral manifestations of PD [42].

The histological study of adrenal medulla of AS/ /AGU rats of the current study showed vascular con- 

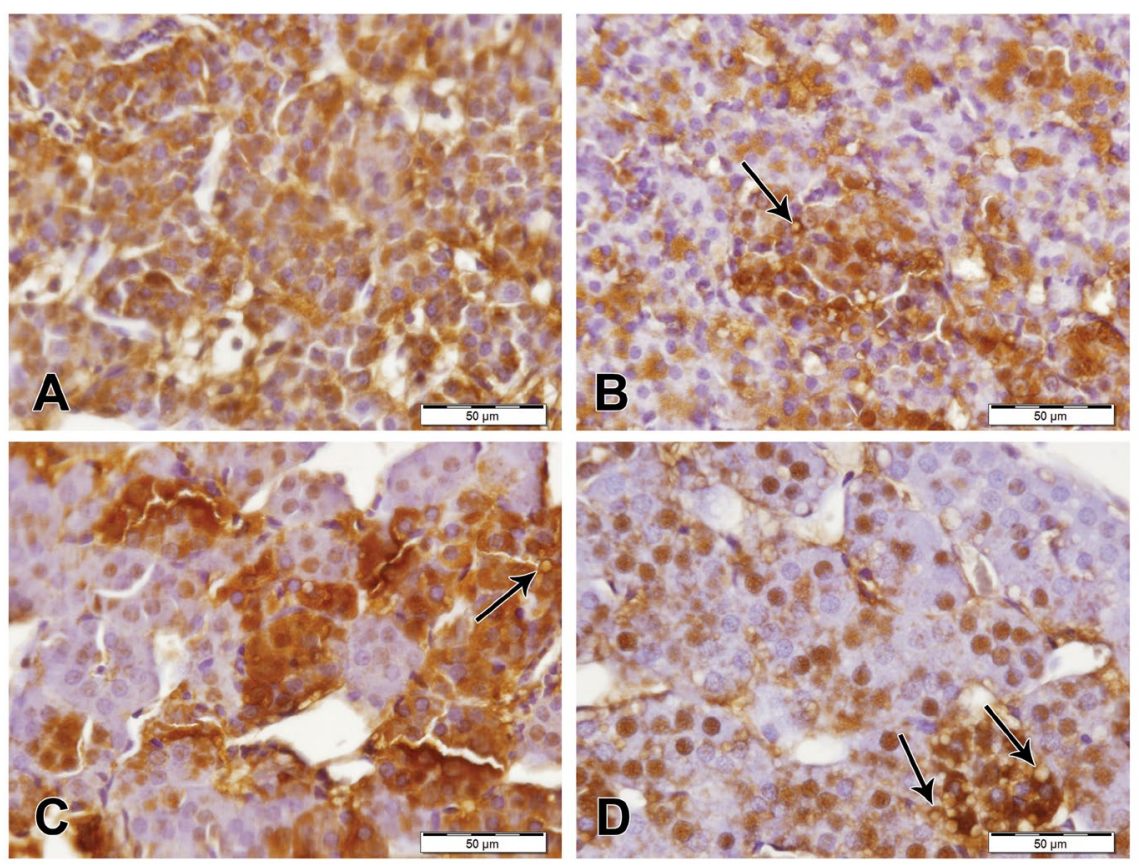

Figure 4. Photomicrographs of ubiquitin immunostained sections of adrenal medulla. Scale bars $=50 \mu \mathrm{m} ; \mathbf{A}$. One-week-old AS rats showing moderate immunostaining; B. One-week-old AS/AGU rats showing moderate immunostaining in few cells and few Lewy's bodies (arrow); C. Adult AS rats showing strong immunostaining of numerous cells. Few cells show Lewy's bodies (arrow); D. Adult AS/AGU rats showing many cells with Lewy's bodies (arrows).
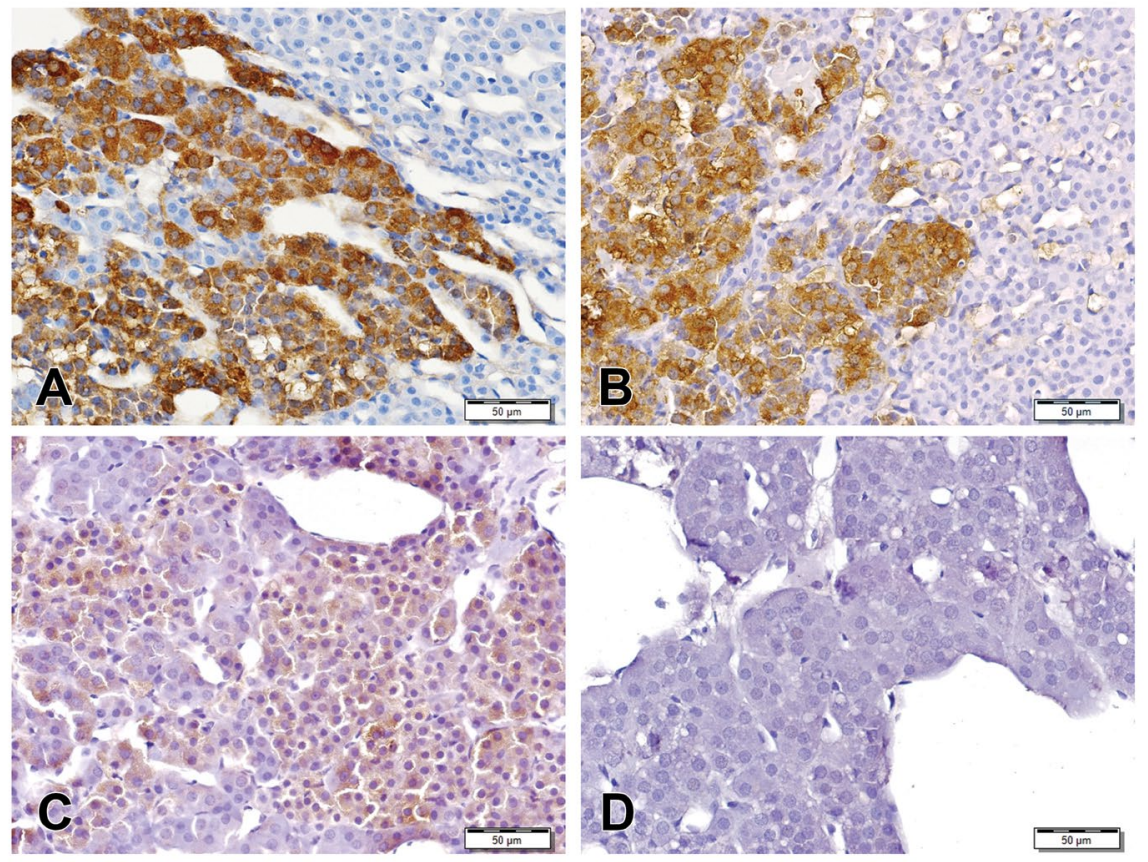

Figure 5. Photomicrographs of tyrosine hydroxylase immunostained sections of adrenal medulla. Scale bars $=50 \mu \mathrm{m} ; \mathrm{A}$. One-week-old AS rats showing strong immunostaining of medullary cells; B. One-week-old AS/AGU rats showing moderate immunostaining of medullary cells; C. Adult AS rats showing mild immunostaining of medullary cells; $\mathbf{D}$. Adult AS/AGU rats showing negative immunoreaction of almost all medullary cells.

gestion, inflammatory cellular infiltration in 1-week-old rats, in addition to foci of necrotic chromaffin cells in adult rats.
The results of the present study were in agreement with others who observed that the progressive degenerative changes affected the neuronal cells of adrenal me- 
A
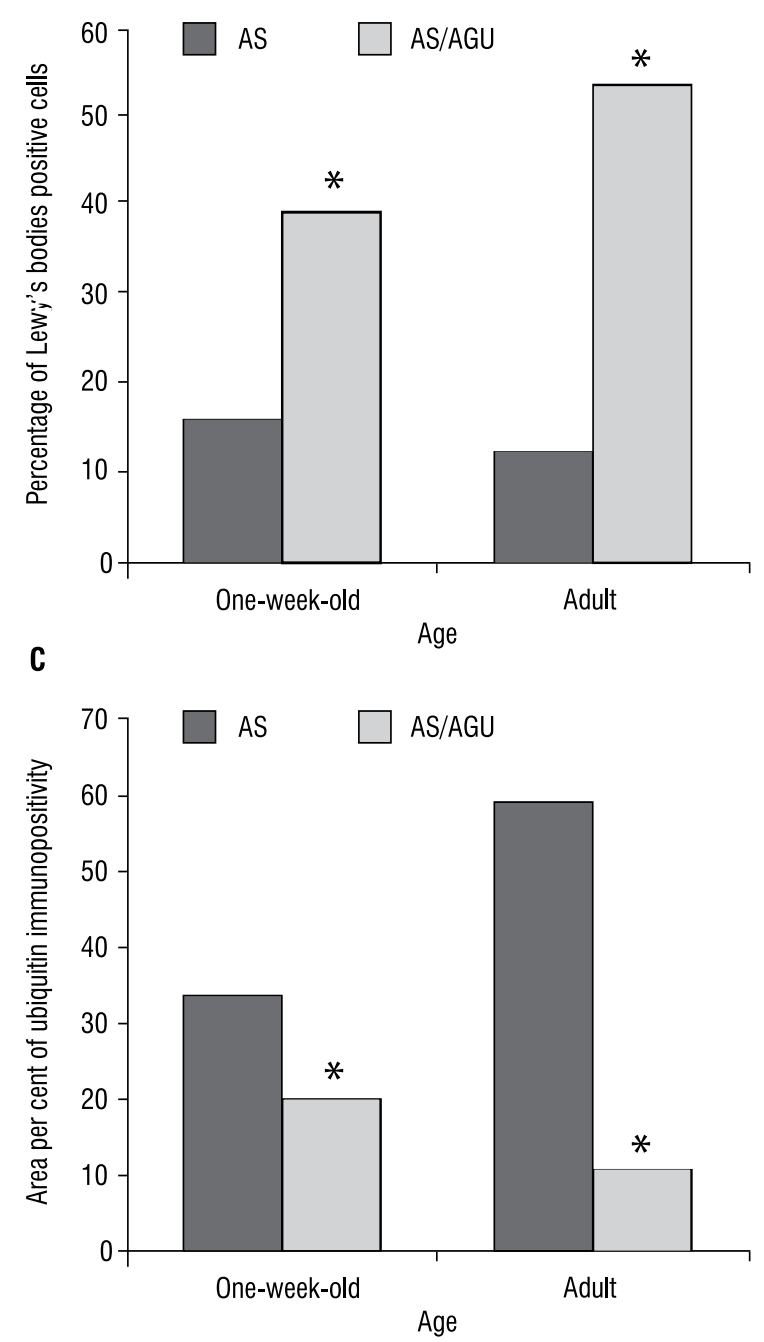

B

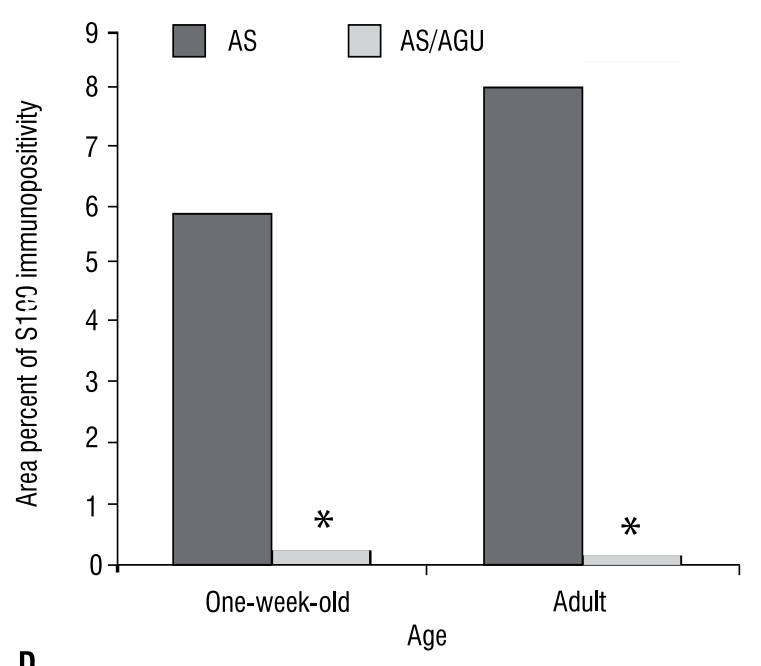

D

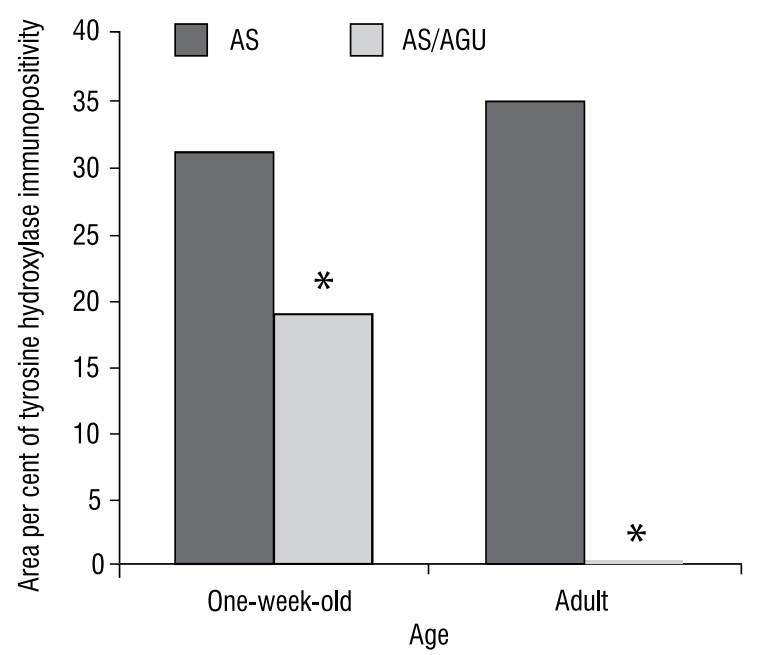

Figure 6. Graphical representation of image analysis data; A. Mean percentage of Lewy's bodies positive cells; B. Mean area per cent of S100 immunopositivity; C. Mean area per cent of ubiquitin immunopositivity; D. Mean area per cent of tyrosine hydroxylase immunopositivity; ${ }^{*}$ Significant difference $(p \leq 0.05)$ between AS/AGU and AS groups.

dulla, similar to other neuronal cells, including the central nervous system (CNS), in PD rat models [21]. The necrotic and apoptotic process is a characteristic pathological picture of neuronal cells in PD [18]. The current study showed that the histological changes in terms of necrosis were more apparent in the AS/AGU adult rats compared to 1-week-old rats. This finding was in agreement with other researchers who revealed increased progression of CNS degeneration with age as a characteristic feature of PD [3]. The aetiology of PD is still unknown but the presence of inflammatory cell infiltrate suggests that it plays an important role in the degeneration of the neuronal cells $[6,7]$. Tumour necrosis factor (TNF)-alpha is the first pro-inflammatory cytokine induced by the inflammatory cell infiltrate, which induces cell death through the activation of TNF-receptors (TNF-R) and consequently stimu- lates and activates apoptotic signal and neuronal death $[4,8,29,32]$. Other pro-inflammatory cytokines which are secreted by inflammatory cell infiltrate, such as interferon gamma and interleukins, are also elevated in brain, blood, and CSF of PD patients [5, 32, 33, 43]. According to these data, these circulating cytokines increasing in the blood can affect the cells of adrenal medulla. The histological changes in AS/AGU rats, in the current study, could be also attributed to the increased free radicals generation and impaired mechanisms of their scavenging. These include enzyme superoxide dismutase, which converts superoxide ions to hydrogen peroxide, and glutathione peroxidase, which enhances the reaction of hydrogen peroxide with reduced glutathione to produce water [18]. These mechanisms may play an important role in the pathogenesis of PD. 
The PAS-stained sections showed marked and more numerous PAS positive stained medullary inclusion bodies in the chromaffin cells of the adrenal medulla of AS/AGU rats. It has been shown that the number of adrenomedullary inclusions per unit area of the adrenal medulla in patients complaining of PD and other Lewy body disorders (LBD) was higher compared to other neurological diseases and apparently healthy subjects without any autonomic dysfunctions, and correlated with the duration of LBD. It was reported that the cells which contain adrenomedullary inclusions are all norepinephrine-secreting chromaffin cells [44]. The presence of adrenomedullary inclusions indicates cellular degeneration which may be ascribed to a defect of norepinephrine reuptake and metabolism [47] or due to a long-term acceleration of the secretion of adrenomedullary norepinephrine in PD resulting in high circulating levels of norepinephrine [44]. The results of the current study revealed an increase in the number of Lewy's bodies in AS/AGU rats compared to AS rats that proportionally increased with age. Young [47] reported that marked and numerous adrenomedullary inclusions are observed in the adrenal glands of people without PD but the accelerated, marked and numerous inclusions are indicating degenerative norepinephrineproducing cells which are a characteristic feature of PD.

The $\mathbf{S 1 0 0}$ immunopositive staining was weakly expressed in sustentacular cells of adrenal medulla of AS/AGU rats compared to the AS rats in different age-groups. The increased expression of S100 plays a role in the pathogenesis of degeneration of dopaminergic neurons at acute phase after 1-methyl4-phenyl-1,2,3,6-tetrahydropyridine (MPTP) treatment [24]. Also, S100-immunopositive cells were found in the striatum and substantia nigra of control mice and increased from first to the third day and then decreased afterward in MPTP-induced PD [35]. Our results failed to find increased expression of $\mathrm{S} 100$ immunopositive cells, which may be due to the fact that we started to investigate the slides by the end of week one.

The current results showed decreased expression of ubiquitin in chromaffin cells of adrenal medulla of AS/AGU rats of both ages compared to the AS rats of both ages. Ubiquitin is an intracellular protein degradation system that is responsible for the majority of protein turnover within the cell [23]. The decreased ubiquitin could be a cause or result of PD in AS/AGU groups of our study.

The presence of ubiquitin positive peripheral expression of the cytoplasmic inclusions indicated the presence of Lewy's bodies, which consist of a heterogeneous mixture of proteins and lipids. Lipids form the core of the inclusions while the peripheral filamentous elements include proteins such as ubiquitin, neurofilament and various proteasomal elements [31]. It was postulated that aberrant proteins accumulate and tend to aggregate when the UPS is impaired [40].

The aggregation of inclusion (Lewy's) bodies indicates increased accumulation of toxic soluble proteins ( $\alpha$-synuclein) in PD [11], which is considered as a protective measure for the neuronal cells. However, excessive build-up of aggregates can also be toxic to cellular functions, resulting in chromaffin cell death.

Our results also showed a weak expression of $\mathrm{TH}$ immunopositive staining in adrenal medulla of AS/ /AGU groups compared to the AS controls. Also, it was noted that the expression of $\mathrm{TH}$ was decreased in AS/AGU adult group compared to 1-week-old group.

$\mathrm{TH}$ is present in all dopaminergic cells, including the adrenal medulla, and catalyses the formation of L-DOPA. It was reported that a deficiency in $\mathrm{TH}$ is a hallmark of PD [1]. It has been noted also that the activities of TH was significantly decreased in the adrenal medulla in patients with PD [38]. The decreased TH activities in AS/AGU adult group compared to AS/AGU 1 week group could be attributed to the progression of $P D$ resulting in decreases in the activities of $\mathrm{TH}$ of the chromaffin cells [22].

\section{Clinical implication}

The histological and immunohistological changes in the adrenal medulla could explain the failure of adrenal autograft therapy in PD.

\section{Limitations of the study}

Our study has some limitations such as neglecting the detection of $\alpha$-synuclein immunohistochemistry to verify the presence of Lewy's bodies, but we believe that ubiquitin immunohistochemistry has the same reliability in this verification. Another limitation of the study is the relatively low number of evaluated animals but that was because of the rarity of the AS/AGU strain. We recommend further studies to be done using different PD animal models to verify our results.

\section{CONCLUSIONS}

As far as we know, this is the first study that extensively investigated the adrenal medulla in PD on histological and immunohistochemical basis. The 
histological and immunohistochemical findings of our study showed that the adrenal medulla is a target for the pathological changes of PD, which may explain the failure of adrenal medulla autograft therapy in PD patients.

\section{Acknowledgements}

The authors extend their appreciation to the Deanship of Scientific Research at King Saud University for funding this work through research group No. (RGP-1438-030).

\section{REFERENCES}

1. Adams JD, Jr., Chang ML, Klaidman L. Parkinson's disease-redox mechanisms. Curr Med Chem. 2001; 8(7): 809-814.

2. Arrasate $M$, Mitra S, Schweitzer ES, et al. Inclusion body formation reduces levels of mutant huntingtin and the risk of neuronal death. Nature. 2004; 431(7010): 805-810, doi: 10.1038/nature02998, indexed in Pubmed: 15483602.

3. Barcia C. Glial-mediated inflammation underlying parkinsonism. Scientifica (Cairo). 2013; 2013: 357805, doi: 10.1155/2013/357805, indexed in Pubmed: 24278772.

4. Beutler B, van Huffel C. Unraveling function in the TNF ligand and receptor families. Science. 1994; 264(5159): 667-668, doi: 10.1126/science.8171316, indexed in Pubmed: 8171316.

5. Blum-Degen D, Müller T, Kuhn W, et al. Interleukin-1 beta and interleukin- 6 are elevated in the cerebrospinal fluid of Alzheimer's and de novo Parkinson's disease patients. Neurosci Lett. 1995; 202(1-2): 17-20, doi: 10.1016/03043940(95)12192-7, indexed in Pubmed: 8787820.

6. Bojinov S, Guentchev T. [Acute encephalitis and myocarditis in a 4 and a half year old infant. (Acute Parkinson syndrome with regressive clinical evolution. Severe myocarditis and bilateral symmetric necrotic inflammation of the locus niger)]. Neuropatol Pol. 1966; 4: Suppl: 655-658.

7. Bojinov $S$. Encephalitis with acute Parkinsonian syndrome and bilateral inflammatory necrosis of the substantia nigra. J Neurol Sci. 1971; 12(4): 383-415, doi: 10.1016/0022510x(71)90109-2, indexed in Pubmed: 4324653.

8. Boka G, Anglade P, Wallach D, et al. Immunocytochemical analysis of tumor necrosis factor and its receptors in Parkinson's disease. Neurosci Lett. 1994; 172(1-2): 151-154, doi: 10.1016/0304-3940(94)90684-x, indexed in Pubmed: 8084523.

9. Campbell JM, Payne AP, Gilmore DP, et al. Neostriatal dopamine depletion and locomotor abnormalities due to the Albino Swiss rat agu mutation. Neurosci Lett. 1996; 213(3): 173-176, doi: 10.1016/0304-3940(96)12852-4, indexed in Pubmed: 8873142.

10. Chen-Pan C, Pan IJ, Yamamoto Y, et al. Prompt recovery of damaged adrenal medullae induced by salinomycin. Toxicol Pathol. 1999; 27(5): 563-572, doi: 10.1177/0192 62339902700510, indexed in Pubmed: 10528636.

11. Ciechanover A, Brundin P. The ubiquitin proteasome system in neurodegenerative diseases: sometimes the chicken, sometimes the egg. Neuron. 2003; 40(2):
427-446, doi: 10.1016/s0896-6273(03)00606-8, indexed in Pubmed: 14556719.

12. Clarke DJ, Payne AP. Neuroanatomical characterization of a new mutant rat with dopamine depletion in the substantia nigra. Eur J Neurosci. 1994; 6(5): 885-888, doi: 10.1111/j.1460-9568.1994.tb01000.x, indexed in Pubmed: 7915606.

13. Cook HC. Manual of histological demonstration techniques. Butterworth-Heinemann, 1974.

14. Coppola D, Fu L, Nicosia SV, et al. Prognostic significance of p53, bcl-2, vimentin, and $\mathrm{S} 100$ protein-positive Langerhans cells in endometrial carcinoma. Hum Pathol. 1998; 29(5): 455-462, doi: 10.1016/s0046-8177(98)90060-0, indexed in Pubmed: 9596268.

15. Coux O, Tanaka K, Goldberg AL. Structure and functions of the $20 \mathrm{~S}$ and $26 \mathrm{~S}$ proteasomes. Ann Rev Biochem. 1996; 65: 801-847, doi: 10.1146/annurev.bi.65.070196.004101, indexed in Pubmed: 8811196.

16. Craig NJ, Durán Alonso MB, Hawker KL, et al. A candidate gene for human neurodegenerative disorders: a rat PKC gamma mutation causes a Parkinsonian syndrome. Nat Neurosci. 2001; 4(11): 1061-1062, doi: 10.1038/nn740, indexed in Pubmed: 11600890.

17. Drury R, Wallington E. Preparation and fixation of tissues. In: Drury R, Wallington E eds. Carleton's histological technique. 5th Ed. Oxford University Press, Oxford, 1980; pp. 41-54.

18. Dunnett SB, Björklund A. Prospects for new restorative and neuroprotective treatments in Parkinson's disease. Nature. 1999; 399(6738 Suppl): A32-A39, doi: 10.1038/399a032, indexed in Pubmed: 10392578.

19. Fitzpatrick KM, Raschke J, Emborg ME. Cell-based therapies for Parkinson's disease: past, present, and future. Antioxid Redox Signal. 2009; 11(9): 2189-2208, doi: 10.1089/ ars.2009.2654, indexed in Pubmed: 19485712.

20. Flatmark T, Almas B, Ziegler MG. Catecholamine metabolism: an update on key biosynthetic enzymes and vesicular monoamine transporters. Ann NY Acad Sci. 2002; 971: 69-75, doi: 10.1111/j.1749-6632.2002.tb04436.x, indexed in Pubmed: 12438092.

21. Hawlitschka A, Haas SJP, Schmitt O, et al. Effects of systemic PSI administration on catecholaminergic cells in the brain, adrenal medulla and carotid body in Wistar rats. Brain Res. 2007; 1173: 137-144, doi: 10.1016/j. brainres.2007.07.072, indexed in Pubmed: 17850771.

22. Haycock JW, Wakade AR. Activation and multiple-site phosphorylation of tyrosine hydroxylase in perfused rat adrenal glands. J Neurochem. 1992; 58(1): 57-64, doi: 10.1111/j.1471-4159.1992.tb09276.x, indexed in Pubmed: 1345770.

23. Hershko A, Ciechanover A. The ubiquitin system. Annu Rev Biochem. 1998; 67: 425-479.

24. Himeda $T$, Watanabe $Y$, Tounai $H$, et al. Time dependent alterations of co-localization of S100beta and GFAP in the MPTP-treated mice. J Neural Transm (Vienna). 2006; 113(12): 1887-1894, doi: 10.1007/s00702-006-0482-x, indexed in Pubmed: 16736245.

25. Hurtig H, Joyce J, Sladek JR, et al. Postmortem analysis of adrenal-medulla-to-caudate autograft in a patient with Parkinson's disease. Ann Neurol. 1989; 25(6): 607-614, doi: 10.1002/ana.410250613, indexed in Pubmed: 2742361. 
26. Kelly PJ, Ahlskog JE, van Heerden JA, et al. Adrenal medullary autograft transplantation into the striatum of patients with Parkinson's disease. Mayo Clin Proc. 1989; 64(3): 282-290, doi: 10.1016/s0025-6196(12)65248-3, indexed in Pubmed: 2649748.

27. Kompoliti K, Chu Y, Shannon KM, et al. Neuropathological study 16 years after autologous adrenal medullary transplantation in a Parkinson's disease patient. Mov Disord. 2007; 22(11): 1630-1633, doi: 10.1002/mds.21528, indexed in Pubmed: 17534949.

28. Kordower $\mathrm{JH}$, Cochran E, Penn RD, et al. Putative chromaffin cell survival and enhanced host-derived TH-fiber innervation following a functional adrenal medulla autograft for Parkinson's disease. Ann Neurol. 1991; 29(4): 405-412, doi: 10.1002/ana.410290411, indexed in Pubmed: 1681779.

29. Larrick JW, Wright SC. Cytotoxic mechanism of tumor necrosis factor-alpha. FASEB J. 1990; 4(14): 3215-3223, doi: 10.1007/978-3-540-29805-2_4659, indexed in Pubmed: 2172061.

30. Madrazo I, Drucker-Colín R, Díaz V, et al. Open microsurgical autograft of adrenal medulla to the right caudate nucleus in two patients with intractable Parkinson's disease. N Engl J Med. 1987; 316(14): 831-834, doi: 10.1056/ NEJM198704023161402, indexed in Pubmed: 3821826.

31. McNaught KS, Mytilineou C, Jnobaptiste R, et al. Impairment of the ubiquitin-proteasome system causes dopaminergic cell death and inclusion body formation in ventral mesencephalic cultures. J Neurochem. 2002; 81(2): 301-306, doi: 10.1046/j.1471-4159.2002.00821.x, indexed in Pubmed: 12064477.

32. Mogi M, Harada M, Riederer $P$, et al. Tumor necrosis factor-alpha (TNF-alpha) increases both in the brain and in the cerebrospinal fluid from parkinsonian patients. Neurosci Lett. 1994; 165(1-2): 208-210, doi: 10.1016/03043940(94)90746-3, indexed in Pubmed: 8015728.

33. Mogi M, Harada M, Narabayashi $H$, et al. Interleukin (IL)-1 beta, IL-2, IL-4, IL-6 and transforming growth factor-alpha levels are elevated in ventricular cerebrospinal fluid in juvenile parkinsonism and Parkinson's disease. Neurosci Lett. 1996; 211(1): 13-16, doi: 10.1016/0304-3940(96)12706-3, indexed in Pubmed: 8809836.

34. Müller T. Drug therapy in patients with Parkinson's disease. Transl Neurodegener. 2012; 1(1): 10, doi: 10.1186/20479158-1-10, indexed in Pubmed: 23211041.

35. Muramatsu $Y$, Kurosaki R, Watanabe $H$, et al. Expression of $\mathrm{S}-100$ protein is related to neuronal damage in MPTPtreated mice. Glia. 2003; 42(3): 307-313, doi: 10.1002/ glia.10225, indexed in Pubmed: 12673835.

36. Payne AP, Sutcliffe RG, Campbell JM, et al. Disordered locomotion in the AS/AGU mutant rat and the effects of L-dopa or fetal midbrain grafts. Mov Disord. 1998;
13(5): 832-834, doi: $10.1002 / \mathrm{mds} .870130514$, indexed in Pubmed: 9756155.

37. Payne AP, Campbell JM, Russell D, et al. The AS/AGU rat: a spontaneous model of disruption and degeneration in the nigrostriatal dopaminergic system. J Anat. 2000; 196 (Pt 4): 629-633, doi: 10.1046/j.1469-7580.2000.19640629.x, indexed in Pubmed: 10923993.

38. Riederer P, Rausch WD, Birkmayer W, et al. CNS Modulation of adrenal tyrosine hydroxylase in Parkinson's disease and metabolic encephalopathies. J Neural Transm Suppl. 1978(14): 121-131, indexed in Pubmed: 39974.

39. Rodriguez H, Filippa V, Mohamed F, et al. Interaction between chromaffin and sustentacular cells in adrenal medulla of viscacha (Lagostomus maximus maximus). Anat Histol Embryol. 2007; 36(3): 182-185, doi: 10.1111/j.1439-0264.2006.00732.x, indexed in Pubmed: 17535349.

40. Sherman MY, Goldberg AL. Cellular defenses against unfolded proteins: a cell biologist thinks about neurodegenerative diseases. Neuron. 2001; 29(1): 15-32, doi: 10.1016/s0896-6273(01)00177-5, indexed in Pubmed: 11182078.

41. Shinzato M, Shamoto M, Hosokawa S, et al. Differentiation of Langerhans cells from interdigitating cells using CD1a and S-100 protein antibodies. Biotech Histochem. 1995; 70(3): 114-118, doi: 10.3109/10520299509108327, indexed in Pubmed: 7548432.

42. Stoddard SL. The adrenal medulla and Parkinson's disease. Rev Neurosci. 1994; 5(4): 293-307.

43. Stypuła G, Kunert-Radek J, Stepień H, et al. Evaluation of interleukins, $\mathrm{ACTH}$, cortisol and prolactin concentrations in the blood of patients with parkinson's disease. Neuroimmunomodulation. 1996; 3(2-3): 131-134, doi: 10.1159/000097237, indexed in Pubmed: 8945728.

44. Sugie M, Goto J, Kawamura M, et al. Increased norepinephrine-associated adrenomedullary inclusions in Parkinson's disease. Pathol. Int. 2005; 55(3): 130-136, doi: 10.1111/j.1440-1827.2005.01800.x, indexed in Pubmed: 15743321.

45. Wijeyekoon R, Barker RA. Cell replacement therapy for Parkinson's disease. Biochim Biophys Acta. 2009; 1792(7): 688-702, doi: 10.1016/j.bbadis.2008.10.007, indexed in Pubmed: 19007882.

46. Wilson AJ, Maddox PH, Jenkins D. CD1a and S100 antigen expression in skin Langerhans cells in patients with breast cancer. J Pathol. 1991; 163(1): 25-30, doi: 10.1002/ path.1711630106, indexed in Pubmed: 2002421.

47. Young J. Catecholamines and the adrenal medulla. Pheochromocytoma. In: Wilson J, Foster D, Kronenberg $\mathrm{H}$, Larson P eds. Williams Textbook of Endocrinology, 1998; pp. 705-728. 